\title{
Vibration Analysis of a Low-Power Reduction Gear
}

\author{
S. Noga ${ }^{1}$ and T. Markowski ${ }^{2}$ \\ Rzeszów University of Technology, Rzeszów, Poland \\ ${ }^{1}$ noga@prz.edu.pl \\ 2 tmarkow@prz.edu.pl
}

Free vibrations of a low-power reduction gear engaged with a hydraulic pump of the test rig are discussed. Vibration analysis is performed with the finite element representation and commercial ANSYS program. Vibration analysis of an examined system is conducted in the two stages. The natural frequencies of free transverse vibrations of the gears are first generated, and on the basis of the Campbell diagrams, the excitation speeds for several natural frequencies of examined gears are calculated. Then the free vibrations of a reduction gear are analyzed, and two computational cases are presented. In the first case, only the mass and geometry of all parts of the body are considered. In the second case, the mass of tooth gears is also taken into account. Based on the FE models, the first ten natural frequencies and natural mode shapes of a reduction gear are calculated. Then, these results are used to estimate the stress level in the walls of the body for a permissible acceleration value. As expected, smaller stress values for a permissible acceleration value are obtained for the second finite element model of the system. The problems discussed here can be helpful for engineers dealing with the dynamics of gear systems.

Keywords: gear resonance, transverse vibration, resonant frequencies, mode shapes.

Introduction. The progress of modern engineering requires technical facilities of high stability and operational reliability. This is especially important for the components and assemblies used in aviation, pharmaceutical industry biotechnology, and biomedical designs. One of the important factors that could upset the normal operation, of the devices (reduction gears and others) are vibrations of the components or assemblies of those systems. The rapid development of computational techniques based on the finite element method (FEM) allows vibration analysis of the systems of complex geometry and design to be conducted [1]. In [2], the finite element (FE) models are used to analyze the static and dynamic behavior of the EDM (electrical discharge machining) machine. The authors [3] analyzed cyclically loaded gear vibrations with a power circulation test rig configuration using FEM techniques. In [4], the simulation method (with FEM solutions) of the fatigue life prediction for dynamic structures is presented. In [5], the FE technique is used to analyze the steady-state vibrations of axisymmetric structures (e.g., toothed wheel with a ring damper). The friction damping effect is also studied. In [6], the FE model of a planetary spur gear designed for vibration analysis is proposed. In [7, 8], the authors examined the dynamic behavior and vibrations of a planetary spur gear with analytical methods. Numerical and experimental investigations focused on assessing the infuence of the local surface damage on the natural vibration frequencies of a full-scale compressor rotor blade are described in [9]. In [10], the transverse vibrations of spur and bevel gears are studied. The FE models of examined wheels are verified by experimental investigations. In $[11,12]$, the FE technique is employed to solve the problem of transverse vibrations of a tooth gear with complex geometry. Here the algorithm to identify the distorted mode shapes is discussed. The transverse vibrations of tooth gears with complex geometry and critical rotational speeds of rotating systems are further discussed [13]. Tooth gears made of nanocomposites are investigated in [14]. In [15], the problem for the transverse vibrations of circular plates with complex geometry is solved with the modified boundary element 
method. The free vibrations of a low-power reduction gear are studied. Analysis is performed with the FE representation and ANSYS program. The major components of the reduction gear are tooth gears and the main body with the cover. At the first stage, the natural frequencies of free transverse vibrations of the gears are determined and the Campbell diagrams are plotted. Then the problems for the free vibrations of a reduction gear are discussed, and the stress level in the walls of the body for a permissible acceleration value is estimated.

1. Statement of the Problem. Vibration analysis of a low-power reduction gear engaged with the hydraulic pump, which is an important auxiliary device of the test rig in aviation industry, is discussed. The reduction gear consists of three meshing tooth gears (Fig. 1a-c). They are supported the by roller bearings, which are located in the bearing block of the body. The body is a complex structure consisting of the main body and the cover (Fig. 1d, e). The cover is attached to the main body with 21 screws, which connect both elements with a designated tightening moment.

The entire unit is attached to the body of the actuating device with the matching sleeve. Power take-off and transfer take place through the additional center shafts, which mate with the gears through the spline couplings. As mentioned above, from the point of view of the considered aspects, the tooth gears (Fig. 1a-c) and the main body with the cover (Fig. 1d, e) are the key component parts. The tooth gears comprise homogeneous material parts with hollow shafts. Moreover, gears Nos. 1 and 3 are adapted to receive and transfer the rotational motion and power to the external devices through the spline couplings. Those gears possess essential geometric similarity (Fig. 1a-c).

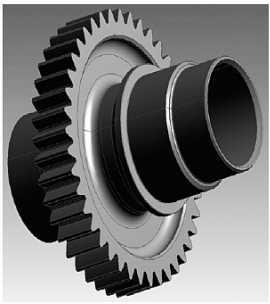

a

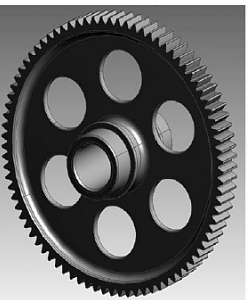

$\mathrm{b}$

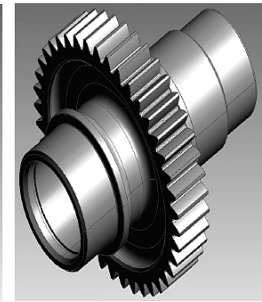

$\mathrm{c}$

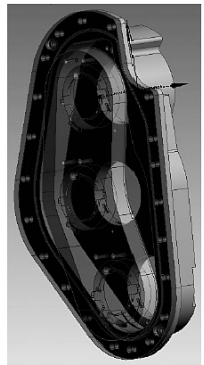

d

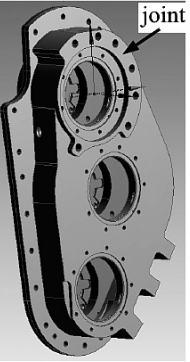

e

Fig. 1. Geometrical model of the tooth gears: (a) gear No. 1; (b) gear No. 2; (c) gear No. 3; geometrical model of the body $(\mathrm{d}, \mathrm{e})$.

2. Finite Element Representations. The numerical FE models of the major component parts of the structure (tooth gears, main body and cover) are first constructed. Simulation and analysis are conducted with an ANSYS program. To build the geometrical models with an optimum number of elements, the surfaces, arising as a result of softening the feather edges, are neglected. In the case of gears, it is mostly applied to softening the tooth points and roots, the splines and undercut of bearing journals. In the case of body elements, the clamping screw holes and geometry of the grease channel are also neglected. In the mesh generation for selected parts, the ten-node tetrahedral element (solid 187) with the three degrees of freedom in each node is used. The FEM models of gears Nos. 1 and 3 (Fig. 2a, c) contain 73,028 elements and 118,848 nodes each. The FE model of gear No. 2 (Fig. 2b) includes 49,810 elements and 89,013 nodes. The numerical model of the main body with the cover (Fig. 2d, e) includes 137,579 elements and 212,388 nodes. In the tooth gear models, the boundary conditions for the nodes are established. In each model, the degrees of freedom related to the radial displacement of the nodes are subtracted from those of the nodes located on the surface of bearing journals. Moreover, in the models of gears Nos. 1 
and 3 , the degrees of freedom related to the longitudinal displacement and rotation of the nodes about the rotation axis of the gears, are subtracted from those of the nodes located on the surface of the spline heads. The mating of the cover and the main body becomes possible due to gluing both elements on the mating surface. Thus, the FEM mesh generation for both elements (adequate for that surface) is provided. Next, the degree of freedom related to the displacement along the rotation axis of gear No. 1, the degree of freedom related to the rotation about that axis and the degree of freedom related to the radial displacement of the mating surface nodes (joint, Fig. 1e) of the same axis, are subtracted from those of the nodes located on the mating surface between the reduction gear and the external device (Fig. 1e or Fig. 2e marked as joint). In the numerical calculations, the two FE models of the reduction gear assembly are examined. In the first model, the geometry and mass of the main body and cover are taken into account.

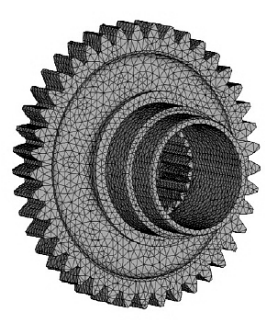

a

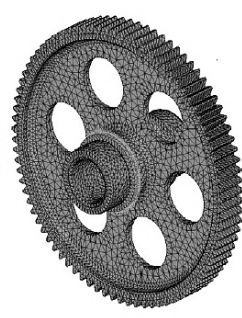

b

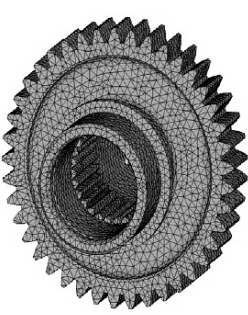

$\mathrm{C}$

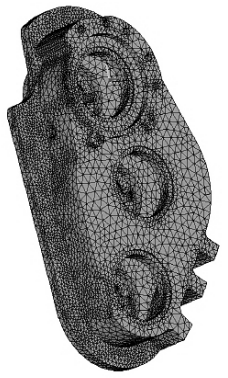

d

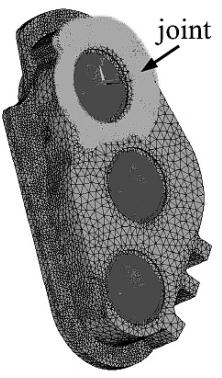

e

Fig. 2. FE models of the following gears: (a) gear No. 1; (b) gear No. 2; (c) gear No. 3; FE models of the body: (d) first FE model; (e) second FE model.

In the second FE model, the mass of the tooth gears of the reduction gear is also taken into account. In this case, the tooth gears are simulated as rigid regions, which include the points wherein the concentrated gear masses are located $[1,3]$.

3. Numerical Analysis. Vibration analysis of the reduction gear unit was conducted in two stages. First, the natural frequencies of transverse vibrations of the tooth gears are generated. During this process, the centrifugal effect is considered. Then the free vibrations of the reduction gear are analyzed. In the case of the tooth gears, the calculation is performed in two steps. The first step is related to static analysis and evaluation of the rotation-induced stress distribution. This distribution is taken into account in the second calculation step, which is related to modal analysis. In compliance with the standards of the circular and annular plate theory [1], each natural frequency is denoted by $\omega_{m n}$, where $m$ is the number of nodal circles and $n$ is the number of nodal diameters. On the basis of the analysis, the Campbell diagram for examined tooth gears is plotted. The occurance of transverse vibrations is most dangerous for the normal operation of the system. The forced frequencies due to the gear meshing may become the source of their excitation $[10,11$, 13]. We distinguish the primary forced frequency due to the gear meshing (first harmonic frequency) derived from the equation $[10,13]$

$$
k_{1}=n_{0} z / 60
$$

and the secondary frequency due to the gear meshing (second harmonic frequency) derived from the equation $[10,13]$

$$
k_{2}=2 n_{0} z / 60,
$$

where $n_{0}(\mathrm{rpm})$ is the rotational speed of the gear and $z$ is the number of gear teeth. 
The resonance may occur when one of the two forced frequencies is equal to one of the frequencies of free vibrations with the change in the rotational speed. The possibility of excitation of vibrations induced by forced frequency (1) is of paramount importance. In this case, the forced frequency due to the meshing is additionally derived from the equation [10]

$$
k_{1}^{*}=\left(n_{0} z \pm n\right) / 60
$$

where $n$ is the number of nodal diameters. Here straight line (1) can be treated as the nominal primary forced frequency due to the meshing. The technical data and operational range of rotational gear speeds are summarized in Table 1.

$\mathrm{T}$ a b 1 e 1

Technical and Operational Data for Tooth Gears

\begin{tabular}{|c|c|c|c|c|c|c|c|c||}
\hline \multirow{2}{*}{$\begin{array}{c}\text { Gear } \\
\text { number }\end{array}$} & $\begin{array}{c}\text { Mass } \\
(\mathrm{kg})\end{array}$ & $z$ & \multicolumn{2}{|c|}{$\begin{array}{c}\text { Rotational speed } \\
(\mathrm{rpm})\end{array}$} & $\begin{array}{c}\text { Module } \\
(\mathrm{mm})\end{array}$ & $\begin{array}{c}\text { Poisson's } \\
\text { ratio } \\
v\end{array}$ & $\begin{array}{c}\text { Young } \\
\text { modulus } \\
E, \mathrm{~Pa}\end{array}$ & $\begin{array}{c}\text { Density } \\
\rho, \\
\mathrm{kg} / \mathrm{m}^{3}\end{array}$ \\
\cline { 3 - 5 } & & $n_{1}$, & $n_{2}$, & & & & & \\
\hline 1 & 1.29 & 41 & 3400 & 6500 & & 0.3 & $2.06 \cdot 10^{11}$ & 7850 \\
\hline 3 & 2.75 & 83 & 1680 & 3211 & 2.5 & 0.3 & \\
\hline
\end{tabular}

The numerical calculations for the gears were restricted to determining the natural frequencies, which would be lower or equal to $\omega_{16}$. The calculations are conducted with the assumption that the gears rotate with the speed within the range from 0 to $n_{2}$ (Table. 1). To account for the centrifugal effect in the calculations, the angular speeds of gears Nos. 1 and 3 increased by $1146 \mathrm{rpm}$ and of gear No. 2 by $859 \mathrm{rpm}$, which gave seven results for gears Nos. 1 and 3 (natural frequencies and corresponding mode shapes) and five ones for gear No. 2, which requires further interpretation. The calculation results are used to plot the Campbell diagrams for each gear. The method of plotting the Campbell diagrams was described in $[10,13]$. Gears Nos. 1 and 3 exhibit significant structural similarity. The calculation results for those gears are also essentially similar. The results of calculations of free vibration frequencies for gears Nos. 1 and 2 are presented in Tables 2 and 3. The analysis of the results demonstrates a marginal impact of rotational speeds on an increase in respective frequencies of free vibrations (moderate increase in the flexural rigidity of the gears).

Moreover, in the case of gear No. 2 we can observe the separation frequency values $\omega_{13}, \omega_{23}$, and $\omega_{16}$. It is caused by the presence of the port holes in the wheel disk. This problem is further discussed in $[11,12,13,15]$.

Next, the results (Tables 2 and 3) are employed to plot the Campbell diagrams for examined tooth gears. The diagrams are used to establish the excitation speeds of respective free vibrations frequencies of examined gears. The Campbell diagram for the range of frequencies from 4600 to $5600[\mathrm{~Hz}]$ for gear No. 1 is shown in Fig. 3.

The diagram analysis demonstrates that the vibration resonance induced by the secondary forced frequency may occur due to the meshing [Eq. (2)] in the operational range of the gear (intersection points of straight line (2) and the curves for the free vibration frequencies). The vertical lines $n k w_{1}, n k w_{2}$, and $n k w_{3}$ in Fig. 3 refer to the excitation speeds of the frequencies $\omega_{11}, \omega_{12}$, and $\omega_{10}$. The excitation speeds of natural frequencies for gear No. 1 are given in Table 4.

The Campbell diagram for the range of frequencies of 2000-3500 [Hz] for gear No. 2 . is illustrated in Fig. 4. In this case, the resonance induced by the forced frequency due to 
T a b 1 e 2

Impact of Rotational Speeds on Natural Frequencies (Gear No. 1)

\begin{tabular}{|c|c|c|c|c|c|c|c|c|c|c||}
\hline \multirow{2}{*}{$\begin{array}{c}\text { RS } \\
(\mathrm{rpm})\end{array}$} & \multicolumn{10}{|c|}{ Natural frequencies $(\mathrm{Hz})$} \\
\cline { 2 - 12 } & $\omega_{11}$ & $\omega_{12}$ & $\omega_{10}$ & $\omega_{13}$ & $\omega_{14}$ & $\omega_{20}$ & $\omega_{21}$ & $\omega_{15}$ & $\omega_{22}$ & $\omega_{16}$ \\
\hline 0 & 4726 & 5347 & 5430 & 10111 & 16821 & 21037 & 24025 & 24199 & 28128 & 31731 \\
\hline 1146 & 4726 & 5347 & 5430 & 1011 & 16822 & 21037 & 24025 & 24199 & 28128 & 31731 \\
\hline 2292 & 4727 & 5347 & 5430 & 10111 & 16822 & 21037 & 24025 & 24199 & 28128 & 31731 \\
\hline 3400 & 4727 & 5348 & 5430 & 10112 & 16822 & 21037 & 24026 & 24199 & 28129 & 31732 \\
\hline 4584 & 4727 & 5348 & 5431 & 10112 & 16822 & 21037 & 24026 & 24200 & 28129 & 31733 \\
\hline 5730 & 4728 & 5349 & 5431 & 10113 & 16823 & 21037 & 24026 & 24200 & 28129 & 31733 \\
\hline 6500 & 4728 & 5350 & 5431 & 10113 & 16823 & 21038 & 24027 & 24200 & 28130 & 31734 \\
\hline \hline
\end{tabular}

Note. $\mathrm{RS}=$ rotational speed.

$\mathrm{T}$ a b 1 e 3

Impact of Rotational Speeds on Natural Frequencies (Gear No. 2)

\begin{tabular}{|c|c|c|c|c|c|c|c|c|c|c|c|c|c|c|}
\hline \multirow{2}{*}{$\begin{array}{c}\mathrm{RS} \\
(\mathrm{rpm})\end{array}$} & \multicolumn{14}{|c|}{ Natural frequencies $(\mathrm{Hz})$} \\
\hline & $\omega_{11}$ & $\omega_{10}$ & $\omega_{12}$ & $\omega_{13}$ & $\omega_{20}$ & $\omega_{21}$ & $\omega_{14}$ & $\omega_{22}$ & $\omega_{23}$ & $\omega_{15}$ & $\omega_{24}$ & $\omega_{30}$ & $\omega_{31}$ & $\omega_{16}$ \\
\hline 0 & 443.2 & 626.2 & 978.9 & $\begin{array}{l}2706 \\
2741\end{array}$ & 4782 & 5045 & 5107 & 5811 & $\begin{array}{l}6402 \\
8811\end{array}$ & 7994 & 9594 & 10347 & 10443 & $\begin{array}{l}11134 \\
11186\end{array}$ \\
\hline 859 & 443.5 & 626.3 & 979.2 & $\begin{array}{l}2706 \\
2741\end{array}$ & 4783 & 5045 & 5107 & 5811 & $\begin{array}{l}6402 \\
8811\end{array}$ & 7994 & 9594 & 10347 & 10443 & $\begin{array}{l}11134 \\
11186\end{array}$ \\
\hline 1680 & 444.3 & 626.6 & 980.0 & $\begin{array}{l}2707 \\
2742 \\
\end{array}$ & 4783 & 5046 & 5108 & 5812 & $\begin{array}{l}6403 \\
8812 \\
\end{array}$ & 7994 & 9595 & 10348 & 10444 & $\begin{array}{l}11134 \\
11187\end{array}$ \\
\hline 2578 & 445.8 & 627.3 & 981.5 & $\begin{array}{l}2708 \\
2743 \\
\end{array}$ & 4784 & 5047 & 5109 & 5813 & $\begin{array}{l}6405 \\
8813 \\
\end{array}$ & 7995 & 9596 & 10349 & 10445 & $\begin{array}{l}11135 \\
11187\end{array}$ \\
\hline 3211 & 447.2 & 627.8 & 983.0 & $\begin{array}{l}2709 \\
2744\end{array}$ & 4786 & 5048 & 5109 & 5815 & $\begin{array}{l}6406 \\
8814\end{array}$ & 7996 & 9597 & 10350 & 10446 & $\begin{array}{l}11136 \\
11188\end{array}$ \\
\hline
\end{tabular}

the meshing [Eq. (1)] with the frequency $\omega_{13}$ in the operational range of the gear can be observed. Therefore, it is necessary to plot additional straight lines [Eq. (3)].

The lines $n w_{2}$ and $n w_{3}$ refer to the nominal excitation speed of the frequency $\omega_{13}$, and the lines $n w_{1}$ and $n w_{4}$ correspond to the excitation speed caused by forced frequency (3). Table 5 presents the excitation speeds of the frequency $\omega_{13}$.

Then the free vibrations of a reduction gear body (Fig. 1d) are analyzed. As mentioned above, at the first step only the mass and geometry of the body are considered, and at the second step the mass of the reduction gear wheels and their location are additionally taken into account. The body was made of an aluminum alloy, having the following characteristics: $E=7.25 \cdot 10^{10} \mathrm{~Pa}, v=0.33, \rho=2790 \mathrm{~kg} / \mathrm{m}^{3}$. The estimated body mass is $14.7 \mathrm{~kg}$. The mass of each gear is set according to Table 1 . The numerical calculations are conducted with the FE models. In both cases, the first ten natural frequencies and corresponding mode shapes of free vibrations are determined. The results are summariged in Table 6. 
$\mathrm{T}$ a b 1 e 4

Excitation Speeds of Natural Frequencies (Gear No. 1)

\begin{tabular}{|c|c|c|c|}
\hline \multirow{2}{*}{ Forced frequency } & \multicolumn{3}{|c|}{ Excitation speed (rpm) } \\
\cline { 2 - 4 } & $n k w_{1}$ & $n k w_{2}$ & $n k w_{3}$ \\
\cline { 2 - 4 } & 3460 & 3914 & 3975 \\
\hline$k_{2}$ & $\omega_{11}$ & $\omega_{12}$ & $\omega_{10}$ \\
\hline
\end{tabular}

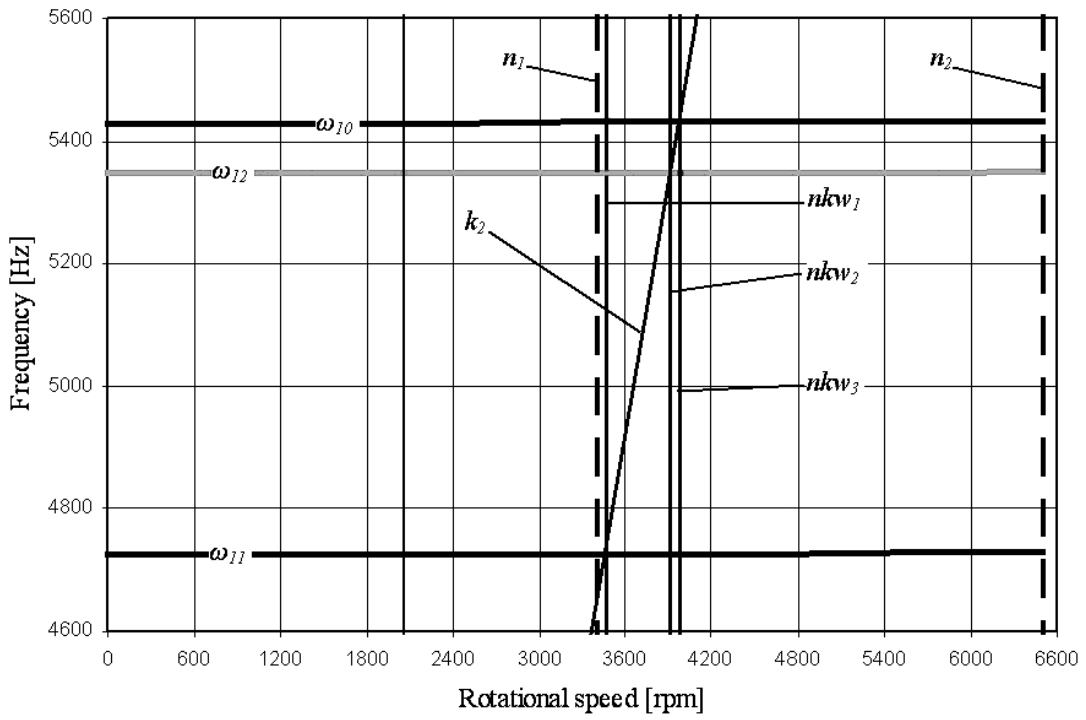

Fig. 3. The Campbell diagram of gear No. 1.

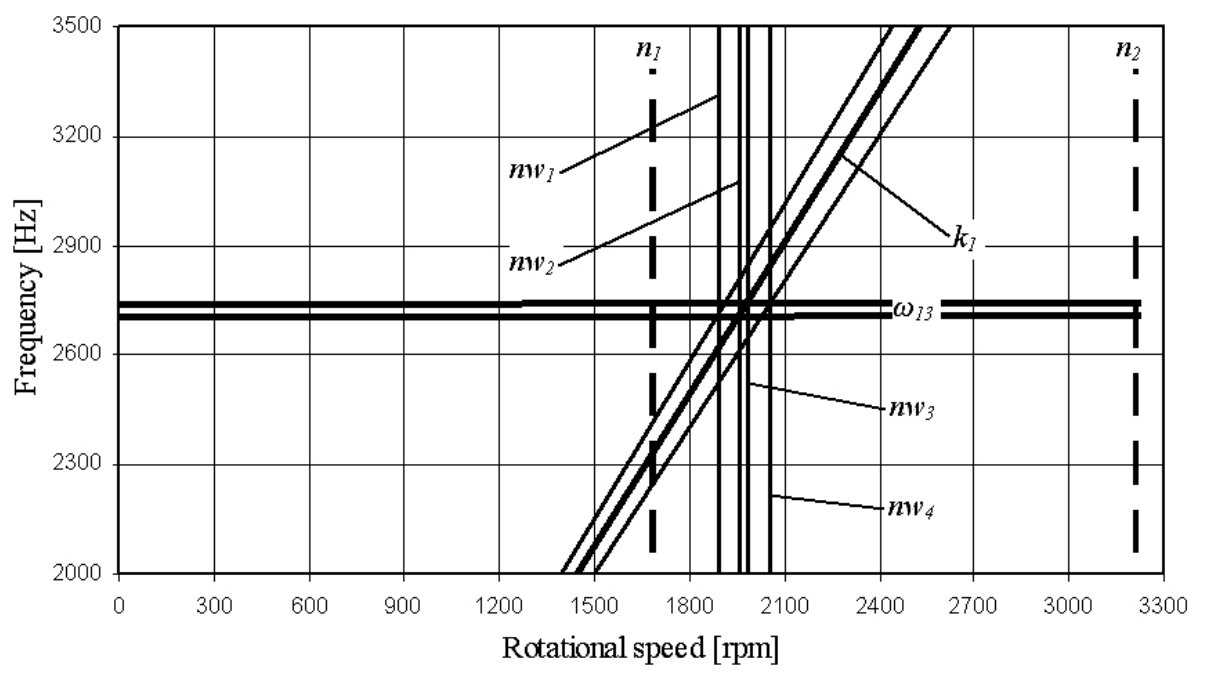

Fig. 4. The Campbell diagram of gear No. 2.

The first two mode shapes generated with the constructed models are shown in Fig. 5. It should be noted that the shapes of corresponding natural modes obtained with the first and second FE models were similar. The natural frequencies obtained with the second FE 
$\mathrm{T}$ a b 1 e 5

Excitation Speeds of the Natural Frequency $\omega_{13}$ (Gear No. 2)

\begin{tabular}{|c|c|c|c|c|}
\hline \multirow{2}{*}{$\begin{array}{c}\text { Forced } \\
\text { frequency }\end{array}$} & \multicolumn{4}{|c|}{ Excitation speed (rpm) } \\
\cline { 2 - 5 } & $n w_{1}$ & $n w_{2}$ & $n w_{3}$ & $n w_{4}$ \\
\cline { 2 - 5 } & 1889 & 1959 & 1984 & 2056 \\
\hline$k_{1}$ & & $\omega_{13}$ & $\omega_{13}$ & $\omega_{13}$ \\
\hline$k_{1}^{*}$ & $\omega_{13}$ & & & \\
\hline
\end{tabular}

$\mathrm{T}$ a b 1 e 6

Natural Frequencies and Mode Shapes of Free Vibrations of the Reduction Gear

\begin{tabular}{|c|c|c|c|c|c|c|c|c|c|c||}
\hline \multirow{2}{*}{$\begin{array}{c}\text { Mode } \\
\text { number }\end{array}$} & \multicolumn{10}{|c|}{ First FE model } \\
\cline { 2 - 12 } & P1 & P2 & P3 & P4 & P5 & P6 & P7 & P8 & P9 & P10 \\
\hline$\omega^{p}, \mathrm{~Hz}$ & 419 & 596 & 1153 & 1750 & 1864 & 2081 & 2265 & 2807 & 2996 & 3113 \\
\hline \multirow{2}{*}{$\begin{array}{c}\text { Mode } \\
\text { number }\end{array}$} & \multicolumn{10}{|c|}{ Second FE model } \\
\cline { 2 - 12 } & D1 & D2 & D3 & D4 & D5 & D6 & D7 & D8 & D9 & D10 \\
\hline$\omega^{d}, \mathrm{~Hz}$ & 679 & 830 & 1601 & 2291 & 2997 & 3115 & 3701 & 3967 & 4757 & 4969 \\
\hline \hline
\end{tabular}

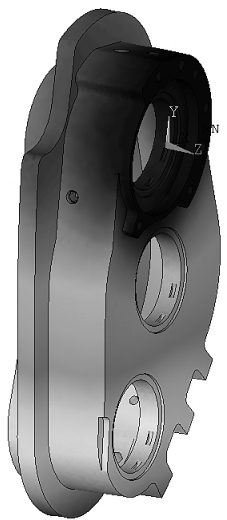

$\mathrm{a}$

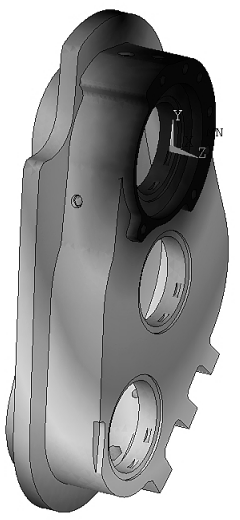

$\mathrm{b}$

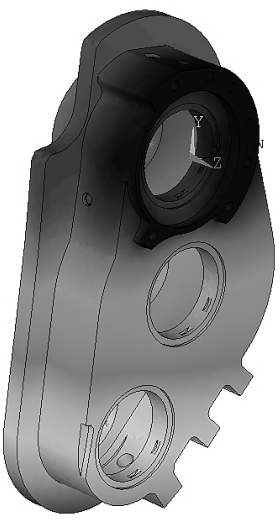

$\mathrm{c}$

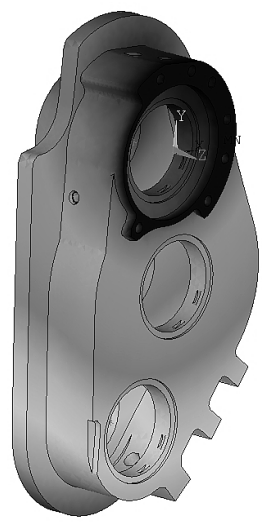

d

Fig. 5. Mode shapes: (a) P1; (b) P2; (c) D1; (d) D2.

model (despite larger mass) are much higher than those calculated with the first one (Table 6). The mobile parts of the reduction gear operate within the range of rotational speeds from 1679 to $6500 \mathrm{rpm}$, which is equal to the following number of cycles: 28-108 Hz. The rotational speeds exciting the natural frequency $\omega_{13}$ of gear No. 2 falls into this range. All frequencies of free vibrations of the body (Table 6) are above the operational range of the mobile parts of the reduction gear.

At the next step of calculations, the stress level for permissible acceleration is estimated. For the reduction gear operation (stationary stand) the permissible acceleration equals $2 g$, where $g=9.81 \mathrm{~m} / \mathrm{s}^{2}$. For several natural frequencies the relative acceleration $p_{0}$ is calculated by the equation

$$
p_{0}=b \omega^{2},
$$


where $b$ is the maximum relative displacement for a given mode shape and $\omega$ is the natural frequency for a given mode shape. Next, the coefficient $k_{w}$ is calculated by the equation

$$
k_{w}=\frac{p_{0}}{2 g} .
$$

Dividing the maximum value of the relative von Mises stress by $k_{w}$, which is established for a given natural frequency by the FE solution, a so-called maximum stress value for permissible acceleration is obtained. This value is compared with the ultimate fatigue strength of the body material. Maximum stresses for permissible acceleration values set for given natural frequencies are presented in Table 7.

Analysis of the results demonstrates slightly smaller stresses for permissible acceleration values in the second FE model. For each natural frequency (Table 7) the maximum stress for a permissible acceleration value is smaller than the ultimate fatigue strength of the body material.

$\mathrm{T}$ a b 1 e 7

Stress Levels for Permissible Acceleration Values

\begin{tabular}{||c|c|c|c|c|c|c|c||}
\hline \multicolumn{4}{|c|}{ First FE model } & \multicolumn{4}{c||}{ Second FE model } \\
\hline $\begin{array}{c}\text { Mode } \\
\text { number }\end{array}$ & $\begin{array}{c}b, \\
\mathrm{~m}\end{array}$ & $\begin{array}{c}\sigma_{\text {Mises }}^{\text {rel }}, \\
\mathrm{Pa}\end{array}$ & $\begin{array}{c}\sigma_{\max }, \\
\mathrm{Pa}\end{array}$ & $\begin{array}{c}\text { Mode } \\
\text { number }\end{array}$ & $\begin{array}{c}b, \\
\mathrm{~m}\end{array}$ & $\begin{array}{c}\sigma_{\text {Mises }}^{\text {rel }}, \\
\mathrm{Pa}\end{array}$ & $\begin{array}{c}\sigma_{\max }, \\
\mathrm{Pa}\end{array}$ \\
\hline P1 & 0.5807 & $2.95 \cdot 10^{11}$ & $1.44 \cdot 10^{6}$ & $\mathrm{D} 1$ & 0.5308 & $4.20 \cdot 10^{11}$ & $8.53 \cdot 10^{5}$ \\
\hline P2 & 0.4864 & $1.93 \cdot 10^{11}$ & $5.56 \cdot 10^{5}$ & $\mathrm{D} 2$ & 0.4850 & $4.29 \cdot 10^{11}$ & $6.39 \cdot 10^{5}$ \\
\hline P3 & 0.6479 & $3.78 \cdot 10^{11}$ & $2.18 \cdot 10^{5}$ & $\mathrm{D} 3$ & 0.7389 & $5.02 \cdot 10^{11}$ & $1.32 \cdot 10^{5}$ \\
\hline P4 & 0.5406 & $5.72 \cdot 10^{11}$ & $1.72 \cdot 10^{5}$ & $\mathrm{D} 4$ & 0.3597 & $8.43 \cdot 10^{11}$ & $2.22 \cdot 10^{5}$ \\
\hline P5 & 0.5791 & $5.10 \cdot 10^{11}$ & $1.26 \cdot 10^{5}$ & $\mathrm{D} 5$ & 0.6402 & $1.32 \cdot 10^{12}$ & $1.14 \cdot 10^{5}$ \\
\hline P6 & 0.5099 & $6.33 \cdot 10^{11}$ & $1.42 \cdot 10^{5}$ & $\mathrm{D} 6$ & 0.5046 & $1.17 \cdot 10^{12}$ & $1.19 \cdot 10^{5}$ \\
\hline P7 & 1.0980 & $8.86 \cdot 10^{11}$ & $7.82 \cdot 10^{5}$ & $\mathrm{D} 7$ & 1.5620 & $1.28 \cdot 10^{12}$ & $2.97 \cdot 10^{4}$ \\
\hline P8 & 0.9429 & $5.52 \cdot 10^{11}$ & $3.69 \cdot 10^{5}$ & $\mathrm{D} 8$ & 2.5880 & $1.84 \cdot 10^{12}$ & $2.25 \cdot 10^{4}$ \\
\hline P9 & 0.6480 & $5.74 \cdot 10^{11}$ & $4.90 \cdot 10^{5}$ & $\mathrm{D} 9$ & 1.8410 & $1.31 \cdot 10^{12}$ & $1.56 \cdot 10^{4}$ \\
\hline P10 & 0.6799 & $8.59 \cdot 10^{11}$ & $6.48 \cdot 10^{5}$ & $\mathrm{D} 10$ & 0.8737 & $1.42 \cdot 10^{12}$ & $3.27 \cdot 10^{4}$ \\
\hline
\end{tabular}

Note: $b$ is the relative displacement, $\sigma_{\text {Mises }}^{\text {rel }}$ is the relative von Mises stress, and $\sigma_{\max }$ is the maximum stress value corresponding to a permissible acceleration value.

Conclusions. The design and developinant of modern facilities (e.g., modern reduction gears) require advanced computational techniques based on the finite element method. It permits considering the specific features and complex geometry of those facilities at the design stage. Here the free vibrations of a low-power reduction gear of a complex design and geometry are analyzed. The free transverse vibrations of rotating tooth wheels of the reduction gear and free vibrations of the reduction gear assembly are discussed. Two FE models for the reduction gear are considered. As is shown, the Campbell diagram is a very useful tool for the vibration analysis of rotating systems (especially tooth gears). The possibility of exciting the natural frequency $\omega_{13}$ of gear No. 2 by the primary forced frequency due to the meshing in the operational range does exist. Slightly smaller stresses for permissible acceleration values of the second FE model for the reduction gear can also be noticed. For verifying the system vibration levels in the 
rotational speed range, the experimental tests are recommended. It should be noted that the this investigation can be helpful for design engineers dealing with the dynamics of complex systems.

1. C. W. de Silva, Vibration and Shock Handbook, Taylor \& Francis, Boca Raton, FL (2005).

2. J. H. Wang, G. Li, Z. F. Liu, et al., "Studies of static and dynamic characteristics of the EDM machine based on the ANSYS workbench," Strength Mater., 47, No. 1, 87-93 (2015).

3. T. Markowski, S. Noga, and S. Rudy, "Modelling and vibration analysis of some complex mechanical systems," in: N. Baddour (Ed.), Recent Advances in Vibrations, Intech Open Access Publisher, Rijeka (2011), pp. 143-168.

4. Wenli Zhao, Xiaojun Zhou, and Meina Shen, "A metchod of virtual design of the fatigue life of a dynamic structure," Strength Mater., 47, No. 3, 507-513 (2015).

5. X. W. Tangpong, J. A. Wickert, and A. Akay, "Finite element model for hysteretic friction damping of traveling wave vibration in axisymmetric structures," J. Vib. Acoust., 130, No. 1, 011005-011005-7 (2008).

6. S. Wang, M. Huo, C. Zhang, et al., "Effect of mesh phase on wave vibration of spur planetary ring gear," Eur. J. Mech. A/Solid, 30, No. 6, 820-827 (2011).

7. D. R. Kiracofe and R. G. Parker, "Structured vibration modes of general compound planetary gear systems," J. Vib. Acoust., 129, No. 1, 1-16 (2007).

8. X. Wu and R. G. Parker, "Modal properties of planetary gears with an elastic continuum ring gear," J. Appl. Mech., 75, No. 3, 031014-031014-12 (2008).

9. A. P. Zinkovskii, I. G. Tokar', and V. A. Kruts, "Influence of the local surface damage parameters on the natural frequencies of vibration of structural elements," Strength Mater., 47, No. 2, 221-226 (2015).

10. R. J. Drago and F. W. Brown, "The analytical and experimental evaluation of resonant response in high-speed, lightweight, highly loaded gearing," J. Mech. Des., 103, No. 2, 346-356 (1981).

11. R. Bogacz and S. Noga, "Free transverse vibration analysis of a toothed gear," Arch. Appl. Mech., 82, No. 9, 1159-1168 (2012).

12. S. Noga, T. Markowski, and R. Bogacz, "Method of determining the normal modes of toothed gears with complex geometry," Sci. J. Silesian Univ. Technol. Ser. Transport [in Polish], 89, 119-127 (2015).

13. S. Noga, Analytical and Numerical Problems of Systems with Circular Symmetry Vibrations [in Polish], Publishing House of Rzeszów University of Technology, Rzeszów, Poland (2015).

14. R. Śliwa, M. Oleksy, O. Markowska, et al., "Composites of commercial unsaturated polyester resins containing nanofillers Nanobent ${ }^{\circledR}$. Part II. Nanocomposites with domestic nanofillers applied in Vacuum Casting technology," Polimery, 61, No. 1, 16-23 (2016).

15. H. Vinayak and R. Singh, "Eigensolutions of annular-like elastic disks with intentionally removed or added material," J. Sound Vib., 192, No. 4, 741-769 (1996). 